\title{
Replizierbarkeit - das ewige Totschlagargument gegen die Homöopathie und andere unliebsame Dinge
}

\author{
Harald Walach \\ Forschende Komplementärmedizin, Medical University Poznan, Poznan, Poland
}

Was würden Sie sagen, wenn Ihnen jemand folgende Zahlenreihe (Tabelle 1) zu einer Serie von Replikationsexperimenten unter die Nase hielte? Es handelt sich um das gleiche experimentelle Modell, das 10 Jahre lang insgesamt in 206 Experimenten mit leicht unterschiedlichen Varianten wiederholt wurde.

Insgesamt wurden also 206 Experimente gemacht, von denen 183 positiv ausgingen, also das experimentelle Modell bestätigen, und 23 negativ, also den Befund nicht replizieren konnten. Man sieht, ohne Voreingenommenheit, auf den ersten Blick, dass hier eine klare Datenlage zugunsten des experimentellen Modells vorliegt, oder?

Nun, so einfach ist es mit der Wissenschaft nicht. Das Beispiel stammt aus dem extrem lesenswerten Buch von Harry Collins und Trevor Pinch „The Golem“ [1, S. 17]. Das Experiment behandelt die Übertragbarkeit von Gedächtnisspuren, ein einstmals blühendes Forschungsgebiet der Verhaltenspsychologie. McConnell hatte in den 1960er Jahren gefunden, dass er Planarien, einfache Würmer, drauf trainieren kann, sich auf einen Lichtreiz hin zusammenzuziehen, indem er die Lichtreize mit einem Elektroschock paarte. Als er dann die konditionierten Würmer an andere verfütterte, sagte er, hätten diese auch 1,5-mal so häufig ohne Training auf Lichtreize mit Zusammenziehen reagiert. Interessant wurde es, als andere das mit Säugern taten, Ratten und Mäusen. Das sind die Versuchsreihen, die oben in der Tabelle beschrieben sind. Dabei wurden Ratten oder Mäuse darauf konditioniert, sich z.B. eher einem hellen Gang zuzuwenden (was sie normalerweise nicht tun), und ihre Gehirne oder Extrakte davon wurden dann anderen Ratten oder Mäusen verfüttert. Es tobte ein heftiger Kampf. Ungar, einer der Hauptvertreter der Übertragungsthese von Erinnerungsspuren, der die Tabelle oben erstellt hatte, war der Meinung, das Phänomen sei belegt. Mächtige Gegner dieser These, Avram Goldstein aus Stanford und einige andere hochrangige Forscher, konnten seine Arbeiten nicht bestätigen. Ungars Arbeit wurde zwar in $\mathrm{Na}$ ture publiziert [2], aber mit einem kritischen Gutachterkommentar. Obwohl Ungars Argumente aus heutiger Sicht vernünftig klingen, nahm sie keiner wirklich mehr ernst. Er hatte den Gegnern, die seine Daten nicht repli-

Tabelle 1. Zahlenreihe

\begin{tabular}{lllllllllllll}
\hline & 1965 & 1966 & 1967 & 1968 & 1969 & 1970 & 1971 & 1972 & 1973 & 1974 & 1975 & Alle \\
\hline Positiv & 13 & 13 & 13 & 16 & 23 & 17 & 27 & 13 & 23 & 17 & 8 & 183 \\
\hline Negativ & 1 & 6 & 4 & 5 & 1 & 3 & 1 & 1 & - & - & 1 & 23 \\
\hline
\end{tabular}


zieren konnten, vorgeworfen, sie hätten Methoden verwendet, die das von ihm vermutete sensible Eiweissmolekül zerstörten, ein Peptid, das er als Träger der Gedächtnisspur vermutete und das er Scotophobin nannte. Die Debatte wogte bis zum Tode Ungars im Jahr 1977, wo sie unentschieden beendet wurde. Denn der Biochemiker Ungar hatte Experimente von einer solchen Kostspieligkeit gemacht, dass keiner mehr das Geld dafür auftreiben konnte und wollte. Zehntausende von Mäuseund Rattenhirnen waren in dieser Forschung zerstampft worden und am Ende, als er auf Goldfische umgeschwenkt war, weil die billiger sind und sehr gut in der Farbdiskrimination, reichten ihm auch die 750 g Goldfischgehirn nicht, die er aus gut 17'000 Goldfischen extrahiert hatte, um sein vermutetes Peptid „Chromodiop-

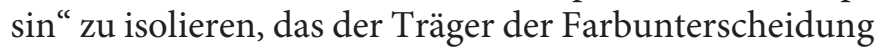
hätte sein sollen. Die Forschung wurde aufgegeben. Die Sache blieb unentschieden, bis zum heutigen Tage, und die Behauptung, die man in manchen Einführungswerken zur wissenschaftlichen Methodik lesen kann, die Wissenschaft habe klar gemacht, dass es Übertragung von Gedächtnisspuren nicht gibt, ist einfach falsch. Die Wissenschaft hat gar nichts klar gemacht in diesem Falle. Sie hat sich einfach anderen Problemen zugewandt und die Frage offen gelassen.

Interessant an dieser Fallvignette aus der jüngeren Wissenschaftsgeschichte der Psychologie ist die Tatsache, dass auch noch so viele positive Befunde, selbst wenn sie in reputablen Zeitschriften publiziert werden, nicht ausreichen. Obwohl die negativen Befunde weniger waren, stammten sie von hoch geachteten Forschern. Und auch wenn die Datenmasse alles andere als überzeugend ist, so ist die informierte Meinung dieser Fachleute wichtig gewesen. Da standen wenige Randgestalten mit einer abgedrehten Theorie gegen eine Überzahl an zentralen Figuren in der Wissenschaftlergemeinde. Möglicherweise hatten die Randgestalten sogar recht. Aber das ist irrelevant.

Man sieht daran: Daten allein sind nicht ausschlaggebend. Daten sind nur ein Element in einem komplexen
Bild. Andere Elemente sind Verstehbarkeit, gute Theorie, soziale Akzeptanz der Daten. Das hat hier gefehlt. Angesichts der Replizierbarkeitsdebatte in der Psychologie und der Medizin ist das ein verwirrender Befund. Wenn sogar ein anscheinend so klares Datenbild nicht zur Akzeptanz eines Befundes führt, was dann? Wie viele Studien muss man denn machen, wie viele Rattenhirne und andere Ressourcen verschwenden? Eine Studie, die die Psychologie aufgerüttelt hat, kam zum Ergebnis, dass weniger als die Hälfte aller experimentellen Paradigmata in der Psychologie replizierbar seien [3]. Dabei reden wir von gerade mal einer Replikation! Ioannidis, der fast alle medizinischen empirischen Daten für unbrauchbar hält, meint generell, medizinische Daten wären nichtssagend [4]. Horton, der Editor von Lancet, beklagt, dass es nirgendwo in der Medizin so robuste Daten gäbe wie in der Physik [5].

Ja, liebe Leute, da ist es kein Wunder, dass es ein Leichtes ist, die Homöopathie totzuschießen. Es geht nämlich gar nie, und sehr selten, wirklich um Daten. Es geht darum, empirische Zusammenhänge zu verstehen, Phänomene einordnen zu können, ein Weltbild und Narrativ zu haben, in das die Erfahrungen hineinpassen, die wir machen. Wer ein Weltbild hatte, in das gedächtnistransferierende Peptide hineinpassen, dem hätten Ungars Daten locker gereicht. Wer ein Weltbild hat, in das krebszelltötende Zytostatika hineinpassen, dem reicht auch eine einzige Studie, die die Überlebenszeit von Krebspatienten um 2 Monate verlängert (egal zu welchen Kosten und mit welchen Nebenwirkungen), um zu behaupten, die Therapie sei wirksam (und der Ansatz insgesamt rational). Und wer ein Weltbild hat, in das nicht-substanzielle Wirkungen, wie sie die Homöopathie behauptet, nicht hineinpasst, dem werden auch tausend Studien nicht reichen.

\section{Disclosure Statement}

Der Autor erklärt, dass keine Interessenkonflikte bestehen.

\section{References}

1 Collins H, Pinch T. The Golem. What You Should Know About Science. Cambridge: Cambridge University Press, 1998 (orig. 1993).

2 Ungar G, Desiderio DM, Parr W. Isolation, identification and synthesis of a specific-behaviour-inducing brain peptide. Nature. 1972 Jul;238(5361):198-202.
3 Open Science Collaboration. PSYCHOLOGY. Estimating the reproducibility of psychological science. Science. 2015 Aug;349(6251): aac4716.

4 Ioannidis JP. Why most published research findings are false. PLoS Med. 2005 Aug;2(8): e124.

5 Horton R. Offline: what is medicine's 5 sigma? Lancet. 2015;385(9976):1380. 